\title{
Rhetorical questions as aggressive, friendly or sarcastic/ironical questions with imposed answers
}

\author{
Džemal Špago \\ Džemal Bijedić University of Mostar, Bosnia and Herzegovina
}

\begin{abstract}
Rhetorical questions (RQs), as a cross-breed of questions and statements, represent an effective tool in putting forward the Speaker's ideas, as well as influencing the ideas and opinions of other people. Because of their communicative effectiveness and multifunctionality, they are frequently used in different contexts and for different purposes, and, as such, they represent an interesting topic for further research. The aim of this paper is threefold: (i) to explore the nature of the implied answer to RQs, (ii) to offer a classification of RQs based on the Speaker's communication style, and (iii) to examine whether (or to what extent) the Speaker-Addressee relationship (peer-to-peer, superior-to-inferior, inferior-to-superior) influences the selection and frequency of use of different types of RQs. Using Stalnaker's (2002) model of Common Ground and Caponigro and Sprouse's (2007) concepts of Speaker's and Addressee's Beliefs, the author redefines the nature of the answers implied by RQs, claiming that they are imposed on the Addressee rather than mutually recognized as obvious. Based on the model of communication styles as defined by Yuan et al. (2018), RQs are classified into aggressive, friendly and sarcastic/ironical questions with imposed answers. The analysis of the corpus, which consisted of 275 RQs taken from ten American movie scripts, showed that friendly RQs are more common than the other two types, and that, in instances where one of the interlocutors is in a superior position, superior-to-inferior RQs are by far more common than vice versa. The finding that RQs asked by inferiors make up less than a third of RQs occurring between interlocutors with different social standing is in line with the view that answers to RQs are imposed on Addressees.
\end{abstract}

Key words: rhetorical question; imposed answer; aggressive rhetorical question; friendly rhetorical question; sarcastic/ironical rhetorical question; peer-to-peer rhetorical questions; superior-to-inferior rhetorical questions; inferior-to-superior rhetorical questions.

\section{Introduction}

Rhetorical questions (henceforth, RQs) represent a cross-breed of questions and statements, simultaneously containing and lacking some elements of both categories. Due to their dual nature, multifunctionality and persuasive power (Frank, 1990; Ilie, 1994), they are frequently utilized by all types of 
language users in everyday conversations and on social networking sites, as well as in different professional contexts, including marketing, politics, journalism, and many other areas of life. While they can get answered by both the Speaker and Addressee (Ilie, 1994), they are generally viewed as questions that do not seek a verbalized answer, ${ }^{1}$ but instead serve to fulfill other communicative goals, which can sometimes even seem conflicting, such as mitigating criticism and emphasizing statements (Frank, 1990).They can also serve as successful and legitimate answers to standard (answer-eliciting) questions, as elaborated by Schaffer (2005). ${ }^{2}$ Furthermore, RQs often incorporate irony and sarcasm (Ilie, 1994; Oraby et al., 2016).

Considering their widespread use, function-form dichotomy, and communicative effectiveness, it is no wonder that, for many researchers, RQs have been an appealing and riveting topic, yet the one that always seems to elude any comprehensive and all-encompassing account, and leaves room for further research.

The goals of this paper are the following: (i) to show that, contrary to the accounts of some previous studies (Rohde, 2006; Caponigro \& Sprouse, 2007), the implied answers to RQs are not necessarily shared and obvious to both the Speaker and Addressee, but rather imposed on the latter; (ii) to provide a classification of RQs based on different communication styles utilized by the Speaker, and the implications of the imposed answer; and (iii) to explore the use of the different types of RQs (aggressive, friendly, and sarcastic/ironical) between interlocutors with different social standing (peer-topeer, superior-to-inferior, and inferior-to-superior), based on a corpus that consists of RQs taken from ten movie scripts.

\section{Background}

A common approach to the analysis of RQs is to treat them as questions that are semantically equivalent to assertions of opposite polarity (Sadock, 1974; Han, 2002):

What has John ever done for Sam? (is equivalent to John has never done anything for Sam.)

\footnotetext{
${ }^{1}$ While most researchers agree that RQs require no answer, Ilie (1994: 82) notes that they ask for a mental response, i.e., "the addressee's recognition of the implicit answer to the rhetorical question."

${ }^{2}$ The obvious answer to an RQ simultaneously provides clear answer to the preceding standard question:

A: How reliable is he? B: How shallow is the ocean? (The ocean is not shallow, and, therefore, the logical answer to the preceding questions is that he is not reliable. The example was taken from Schaffer, 2005: 436).
} 
What hasn't John done for Sam? (is equivalent to John has done everything for Sam. $)^{3}$

The indirect assertion derived from an RQ is based on a single, usually negative, answer in the case of yes-no RQs, or an empty answer set when there is a wh RQ:

Is that what a good friend does? (Single negative answer: No.)

What has he ever done for me? (Empty answer set: Nothing.)

Sadock (1974) provides a test for determining if a question is rhetorical: if it can be preceded by the expression after all, followed by a yet-clause, or if it includes a strong negative polarity item (NPI), ${ }^{4}$ such question can only have rhetorical interpretation. This approach provides a convincing explanation why (unlike standard questions, and just like ordinary statements) RQs can receive responses that show agreement (You're right; I agree; etc.), as well as why they are compatible with words or expressions that introduce statements (after all, because, otherwise), and incompatible with expressions which are indicative of asking for information (by any chance). However, the fact that both the Speaker and the Addressee can opt to take an RQ at the literal level and answer it, just like any other question, presents a challenge to this approach.

Van Rooy (2003) offers a different, and somewhat unexpected, account of RQs, treating them as questions which, just like standard questions, are information-seeking, but have a constrained set of possible answers. Elaborating on RQs that incorporate strong NPIs, he claims that different answers are possible (A: Did he lift a finger to help? B: $\underline{N o} / \underline{Y e s}$ ), but they make little difference (He did nothing or next to nothing).

Rohde treats RQs as uninformative and redundant interrogatives, as they have "a very predictable, obvious answer to which all participants are committed" (2006: 250). According to her, RQs do invoke a set of answers 5 , just like standard questions, but the answer is already known to everyone, and that is what makes them redundant.

\footnotetext{
${ }^{3}$ Examples taken from Han (2002: 202). However, it is possible that an RQ and the equivalent indirect assertion implied by it have the same polarity: the RQ Who fed you and gave you the proper education? (when asked by a parent) is equivalent to I fed you... (Han, 2002: 218).

${ }^{4}$ Polarity items (PIs) are linguistic units that can only be used in negative (NPIs) or positive sentences (PPIs). They can be weak (any, some, etc.) or strong (lift a finger, give a damn, etc.) (Zwarts 1996; Han 2002; and others). Whenever strong NPIs appear in questions, they allow for only one answer, which makes such questions rhetorical in any context.

${ }^{5}$ Rohde (2006: 135) lists four types of answers to RQs: a negative answer (Who lifted a finger to help?/Nobody!); a positive answer (Has the educational system been so watered down that anybody who's above average is now gifted?/Yes!); a non-null answer (Who always shows up late for class?/ You!); and multiple answers (What is going to happen to these kids when they grow up?).
} 
Caponigro and Sprouse (2007) offer an account according to which RQs are semantically the same as standard questions, and the only real difference between the two is at the pragmatic level (the conditions that stipulate their use in a particular context). ${ }^{6}$ They also point out that the answer to an RQ has to be a part of the Speaker and Addressee's common knowledge (of which they are both aware), whether they verbalize it or not. Therefore, under this approach, the purpose of RQs is to put emphasis on something that is already known to both the Speaker and Addressee.

\section{Methodology}

The present research focuses on three points: the nature of the implied answers to RQs, the classification of RQs according to the communication style utilized by the Speaker, and the use of the different types of RQs in different communicative situations, with special focus on the Speaker-Addressee relationship (peer-to-peer, superior-to-inferior, and inferior-to superior).

As for the first point, Stalnaker's (2002) model of Common Ground, ${ }^{7}$ along with the notions of Speaker's Beliefs and Addressee's Beliefs (as presented by Caponigro \& Sprouse, 2007) will be used to counter the claim that implied answers to RQs (invariably) fall within the scope of the interlocutors' common knowledge. These three concepts (Common Ground, Speaker's and Addressee's Beliefs) are convenient for this analysis as they offer a solid basis for handling the Speaker's and Addressee's individual and shared knowledge, which is crucial for determining the nature of the implied answers.

A new classification of RQs will be proposed, with some modifications, on the basis of the model of communication styles as defined by Yuan et al. (2018). Their interpretation, which essentially limits communication styles to only two (the aggressive and polite one), offers a good basis for classifying RQs into those that are used to put down, criticize or verbally attack the Addressee (or his/her views), and those that represent attempts to draw the Addressee's attention to something, persuade, or affect his/her opinion in a friendly way. Additionally, the third type of RQs will be introduced to ac-

\footnotetext{
${ }^{6}$ While it is often the case that rhetorical and non-rhetorical questions share the same form and semantic content (What's the difference? can be a rhetorical or information-seeking question), a potential problem for this approach is the fact that certain RQs have a specific form which differentiates them from standard questions. For instance, semantic incompatibility may indicate the rhetorical nature of some questions, such as Does a fool know what's good for him? (see Špago, 2017).

${ }^{7}$ The concept of Common Ground (in reference to shared background knowledge) was originally introduced by Paul Grice (Stalnaker, 2002: 701), and it was used by Stalnaker in his previous work.
} 
count for those instances when irony or sarcasm is incorporated into such questions, whether with friendly or aggressive implications.

The corpus for the analysis of aggressive, friendly, and sarcastic/ironical RQs consists of 275 examples of RQs identified in the scripts of ten American movies. As movies reflect real-life events and conversations, the selected examples are expected to offer a reliable insight into the use of different types of RQs in English. The selection of this corpus is motivated by the intention to include diversified communicative situations and different roles and/or relationships of participants in the analysis of the above types of RQs. The criterion used for labeling questions as rhetorical in this study has been that, as suggested by Sadock (1974), they can be preceded by the phrase after all and/or followed by a yet-clause. Additionally, questions that show the Speaker's shock or surprise (Are you crazy? and its equivalents) have also been included. ${ }^{8}$ The identified RQs have been classified into the above types (aggressive, friendly, and sarcastic/ironical) with the help of 10 respondents. The respondents were fluent English speakers with university degrees in language/linguistics. While blatant examples of aggressive and friendly RQs have been classified by the author (for instance, What the hell does it matter how much money I make? - aggressive; Who could resist his charm? - friendly), the respondents' answers were used to identify all sarcastic/ironical RQs, as well as those aggressive and friendly RQs that might be treated as borderline cases. The respondents were presented with those RQs as used in a particular context, accompanied with preceding and following content. In case of the difference of opinion, the majority opinion has been taken as valid.

The identified RQs have been further analyzed based on the SpeakerAddressee relationship (peer-to-peer, superior-to-inferior, and inferior-tosuperior) in order to explore whether (and, if yes, to what extent) the roles of interlocutors affect the frequency and selection of the different types of RQs.

\section{Results and discussion}

\subsection{RQs as questions with imposed answers}

One of the key differences between rhetorical and standard questions is the expectance of an answer. While standard questions seek to elicit an (informative) answer, RQs already imply an answer which seems obvious to everyone. Therefore, as noted above, Rohde (2006) and Caponigro and Sprouse (2007) claim that answers implied by RQs are a part of the Speaker's

\footnotetext{
8 They cannot be accompanied by the expression or not, which is another indicator that a question is rhetorical, according to Sadock (1974).
} 
and Addressee's Common Ground, ${ }^{9}$ which Stalnaker (2002: 704) defines as "mutually recognized shared information" between the participants. However, the assumption that Speaker's and Addressee's Beliefs are shared in regard to a specific RQ is taken by the Speaker. Therefore, a potential challenge to interpreting implied answers to RQs as a part of the shared knowledge of the participants is the fact that, as noted by Stalnaker (2002), the Speaker may just pretend or presume that something is a part of the Common Ground when it is not. In the case of RQs, it means that the implied answer is just presented as obvious by the Speaker, whether it is a part of the Addressee's Beliefs or not. For instance, the following (invented) example of an RQ implies an answer which would not be shared by most people:

a) Who can say with certainty that global warming is an imminent threat? Yet we hear about it all the time. (The implied answer: Nobody. The Addressee's Belief: Many people./Everybody.)

Or, if we consider a more likely example:

b) You know you can always count on me. After all, have I ever let you down? (The implied answer: No. The Addressee's Belief: No./Yes./Couple of times./Many times.)

The following RQ from the corpus (a prison guard is addressing a prisoner) also implies an answer (the Speaker should not believe the Addressee) which is not shared by both interlocutors:

(1) HADLEY: You're the smart banker what shot his wife. Why should I believe a smart banker like you? So's I can wind up in here with you? (The Shawshank Redemption)

According to Rohde's (2006) approach, the examples in which the Addressee's Beliefs are different from the implied answer would count as failed RQs, along with questions that were intended as rhetorical, but understood and answered as information-eliciting by the Addressee. However, there is a number of reasons why such interpretation does not seem convincing:

- the Speaker often goes on talking, and leaves no room for the Addressee to reject the implied answer if it is not shared (we would never find out if such RQs are failed or not);

- the Addressee may choose not to counter the implied answer for different reasons (not to hurt or anger the Speaker, because it seems irrelevant, etc.) even if the implied answer is not a part of the Common Ground;

\footnotetext{
9 "[E]ach participant knows the answer and they each know that they both know the answer" (Rohde, 2006: 136); RQs "serve only to reiterate information already in the Common Ground" (Rohde, 2006: 152).
} 
- when directed to multiple Addressees (such as on Twitter, or in public talks), the implied answer may be shared by some, but rejected by others (it would mean that the same RQ is failed and successful at the same time), etc.

Therefore, instead of the claim that the implied answer needs to be a part of the Speaker's and Addressee's Beliefs, and thereby their Common Ground (or else it is a failed RQ), I will propose a different view based on Stalnaker's (2002) remarks on the Speaker's pretense or wrong assumptions in regard to the Common Ground: an RQ is a biased question which implies an answer imposed by the Speaker as obvious, whether indeed shared by the Addressee or not. This view allows for a difference of opinion - something that seems obvious to one interlocutor may be completely or partly unacceptable to another. The nature of the imposed answer may vary:

- it may indeed be obvious to any competent language user (Is the sky blue?),

- the Speaker may think that it is obvious to everybody (What can be more important than family?),

- the Speaker may intentionally present something as obvious in order to manipulate the Addressee's opinion, which is particularly convenient in marketing or politics (Where else can you find such a great offer?),

- the imposed answer may reflect the Speaker's anger or annoyance with the Addressee, in which case the intention may be to express negative feelings and hurt the Addressee, rather than to emphasize a mutually recognized fact (What do you know about anything?).

\subsection{Aggressive, friendly and sarcastic/ironical $R Q s$}

One of the goals of this research is to offer a classification of RQs based on the Speaker's communication style, i.e., his/her attitude towards the Addressee or a third party. De Vries et al. (2009: 179) define a communication style as "the way a person sends verbal, paraverbal, and nonverbal signals in social interactions denoting a) who s/he is or wants to (appear to) be, b) how $\mathrm{s} /$ he relates to interactants, and c) in what way his/her literal messages should usually be interpreted." Therefore, it relates to the way in which a message, along with the Speaker's feelings towards the Addressee, is expressed. While different types of communication styles might be identified, ${ }^{10}$ they all, as noted by Yuan et al. (2018) boil down to two basic ones: the aggressive (dominant and forceful), and polite style (friendly and peaceful). ${ }^{11}$

\footnotetext{
${ }^{10}$ For instance, Norton (1983) identifies a number of attributes which define different communication styles: dominant, friendly, contentious, relaxed, dramatic, animated, etc.

${ }_{11}$ Yuan et al. (2018) also note that different terminology is used by different researchers, such as dominance vs. affiliation/supportiveness.
} 
The former is characterized by verbal aggression (attacking a person's character rather than his/her views), language intensity (showing intense emotions), and/or incivility (lack of respect), while the latter is based on a respectful, friendly approach and showing consideration for others. Both of these styles can produce positive or negative communicative effects. The aggressive communication, which is often found in political discourse, can be more powerful and entertaining, and it can attract attention, as well as help the Speaker damage the reputation of the opponents, but, on the other hand, it can also bring into question the Speaker's credibility. In a similar vein, while the polite style can be persuasive and help build closeness with the Addressee, it can potentially be vague and thereby cause some ambiguity (Yuan et al., 2018). They also allow for the third, neutral style, which is neither aggressive nor polite.

I will offer a new classification of RQs which is, with some modifications, based on the two primary communication styles presented above, as they reflect two opposing aspects of RQs which can be utilized in communication - the aggressive and friendly one. While they may still be less forceful than outright statements, aggressive $R Q s$ are used to verbally attack (accuse, criticize, put down, or even insult) the Addressee or a third party, and they reflect the Speaker's dominant attitude and lack of consideration for the Addressee's (or a third party's) feelings. An aggressive RQ is emotionally charged and often presented in a forceful way. Its imposed answer is either biased and subjective, or, if indeed a part of the Common Ground, disconcerting and unpleasant to the Addressee. Therefore, aggressive RQs are particularly convenient in political communication, online forums, or any other context where the Speaker's intention is to discredit or criticize someone:

(2) HOWARD: Who told you you could tell me to shut up? (The Butler)

The second category, which I will name friendly $R Q s$, is based on either polite or neutral communication style, and it includes instances of RQs whose implied answers are not threatening to the Addressee, and which do not express the Speaker's negative attitude. While they can be used to thoughtfully rebut the Addressee's arguments or express disagreement, friendly RQs are never disrespectful, nor charged with negative emotions (anger, annoyance, impatience, etc.). Friendly RQs are particularly convenient in any context that requires respectful attitude towards the addressee, such as advertisement, counseling, friendly talk, etc.

(3) RED: Relax. What are you so nervous about?She's just a woman. (The Shawshank Redemption) 
Finally, the third type, sarcastic/ironical RQs, ${ }^{12}$ includes those instances where such questions incorporate irony, either with friendly (example 4) or aggressive undertones (example 5):

(4) SYDNEY: I've gotta nip this in the bud. This has catastrophe written all over it.

BETH: In what language?! Sydney, this man is the leader of the free world. He's brilliant, he's funny, he's handsome, and he's an above-average dancer. (The American President)

(5) RUSSELL: Burton says it's a flesh wound --

RICHMOND: -- when did you become such an expert, Bill?-- Ever been wounded? -(Absolute Power)

According to Roberts \&Kreuz (1994), out of seven other figurative language forms (understatement, metaphor, irony, simile, idiom, indirect request), the highest likelihood of overlap is between RQs and irony, which indicates that sarcastic/ironical RQs are commonl used. While examples in which irony is used in a friendly way can be found, it is much more likely for such RQs to incorporate sarcasm, and thereby to adhere to the aggressive communication.

\subsection{Use of aggressive, friendly, and sarcastic/ironical RQs in the selected movie scripts}

In this section, I will analyze the use of the above three types of RQs in the corpus that included ten American movie scripts, while focusing on the nature of the relationship between the interlocutors (peer-to-peer, superior-toinferior, and inferior-to-superior) and its potential impact on the type and frequency of use of different RQs.

Altogether, 275 examples ${ }^{13}$ of RQs have been identified in the corpus and, according to the obtained results, the most common type is friendly RQs, followed by aggressive and sarcastic/ironical, as shown in Table $1 .{ }^{14}$

\footnotetext{
${ }^{12}$ Gibbs (2000) lists RQs as one of the subtypes of irony, along with sarcasm (which represents an aggressive type of irony meant to mock something or someone), jocularity, hyperbole, and understatements.

1335 of them were strings of two or more questions. As each string includes RQs of the same type, they were treated as one example in this research.

${ }^{14}$ Table 1 does not include RQs from monologs (7 examples). The same applies for Table 3.
} 
Table 1: Frequency of occurrence of different types of RQs in the selected corpus.

\begin{tabular}{|l|c|}
\hline Type of RQs & Frequency of occurrence in the corpus \\
\hline Friendly & $140(52.23 \%)$ \\
\hline Aggressive & $89(33.2 \%)$ \\
\hline Sarcastic/ironical & $39(14.55 \%)$ \\
\hline
\end{tabular}

The aggressive RQs have been used to carry out different sorts of facethreatening acts, 15 including:

- criticizing - When do the rest of us stop paying off your debts? (Nixon),

- accusing - Who has given the Russians the atomic bomb?!(Nixon),

- threatening- You want me to report you to your warden? Is that what you want? (The Shawshank Redemption),

- insulting - Who are you talking to like this, you insignificant shit? (Nixon), etc.

While the use of foul language and expletives has not been prevalent, a significant number of such RQs included it (32 examples, $36.78 \%$ of the aggressive RQs). ${ }^{16}$ Almost a quarter of the aggressive RQs from the corpus referred to a third party (22 examples / $24.71 \%$ ), such as in the following example:

(6) LOU: Correct me if I'm wrong. I thought we were on the same side. What the hell business is it of theirs to say that? (JFK)

As for sarcastic/ironical RQs, most examples from the corpus (27 examples / 69.23\%) represent instances of sarcasm being used in order to put down the Addressee or a third party. Surprisingly, only one sarcastic/ironical RQ included the use of expletives (F-word). Common patterns for such RQs included the use of ironic compliments when criticizing someone (genius, expert, mind-reader, etc.) and providing a ridiculous answer to the $\mathrm{RQ}$, as shown in the following example:

(7) MOSS: I was in Nam.

WELLS: So was I.

MOSS: So what does that make me? Your buddy? (No Country for Old Men)

\footnotetext{
${ }^{15}$ Those (speech) acts that can be threatening to the face (self-image) of either the Speaker (apologizing, thanking, etc.) or Addressee (criticizing, accusing, etc.). The concept was introduced by Brown \&Levinson (1987) within their politeness theory.

${ }^{16}$ The most commonly used expletives were the hell (used in 15 examples), F-word (5), shit/bullshit (4), goddamn/God damned (3), etc.
} 
In line with previous studies (Ivanko et al., 2004), individual differences in the use of sarcasm and irony have been noted, as multiple sarcastic/ironical RQs from the corpus were asked by the same speaker. ${ }^{17}$

As for the roles of interlocutors, most of the identified examples occur in peer-to-peer interactions, which can be explained by the fact that most conversations in the selected corpus are conducted by participants who have equal social status. However, when it comes to those instances in which one of the participants is in a superior position, the use of RQs is much more common in superior-to-inferior communication than vice versa, as shown in Table 2.

Table 2: Frequency of occurrence of RQs in the selected corpus based on the Speaker-Addressee relationship

\begin{tabular}{|l|c|}
\hline $\begin{array}{l}\text { Speaker-Addressee } \\
\text { relationship }\end{array}$ & Frequency of occurrence of RQs in the corpus \\
\hline Peer-to-peer & $157(57.09 \%)$ \\
\hline Superior-to-inferior & $82(29.81 \%)$ \\
\hline Inferior-to-superior & $29(10.54 \%)$ \\
\hline Monolog & $7(2.54 \%)$ \\
\hline
\end{tabular}

If we just focus on those RQs that were used between participants of different social status, superior-to-inferior RQs make up 73.87\% of such examples. We can conclude that the prevalent reason for this discrepancy is that friendly RQs are the most convenient in inferior-to-superior communication, and the other two types can occur only if they relate to a third party, or if the Speaker is openly defying the Addressee's authority.

Table 3 shows the frequency of use of the three types of RQs in regard to the Speaker-Addressee relationship.

Table 3: Frequency of occurrence of the three types of RQs based on the Speaker-Addressee relationship.

\begin{tabular}{|l|c|l|c|}
\hline $\begin{array}{l}\text { Speaker-Addressee } \\
\text { relationship }\end{array}$ & Friendly RQs & $\begin{array}{l}\text { Aggressive } \\
\text { RQs }\end{array}$ & $\begin{array}{l}\text { Sarcastic/ironical } \\
\text { RQs }\end{array}$ \\
\hline $\begin{array}{l}\text { Superior-to-inferior } \\
(82)\end{array}$ & $29(35.36 \%)$ & $39(47.56 \%)$ & $14(17.07 \%)$ \\
\hline $\begin{array}{l}\text { Inferior-to-superior } \\
(29)\end{array}$ & $20(68.96 \%)$ & $4(13.79 \%)$ & $5(17.24 \%)$ \\
\hline Peer-to-peer (157) & $91(57.96 \%)$ & $46(29.29 \%)$ & $20(12.73 \%)$ \\
\hline
\end{tabular}

${ }^{17}$ American President - 5 examples of sarcastic/ironical RQs by the same speaker; Independence Day - 4 examples; Absolute Power - 3 examples; The Program - 2 examples. 
A noteworthy result from the above data is that aggressive RQs were more commonly used than friendly ones in the superior-to-inferior interaction, which can be explained by the fact that the Speaker who is in a superior position generally does not have to worry too much about the Addressee's feelings or reactions.

Another interesting finding is that, even when it comes to friendly RQs, it is more likely that RQs are posed by a superior rather than an inferior, which can correspond with the previously presented view that implied answers to RQs are imposed on the Addressee. Therefore, it seems logical that RQs are less commonly asked by someone who is in an inferior position, as asking RQs (and, thereby, imposing one's view on one's superior) may sometimes look inappropriate, if not disrespectful.

\section{Conclusion}

Unlike standard questions, RQs do not seek to elicit an answer, but rather perform other communicative functions. While such questions are formulated in a way that makes answers to them seem obvious to everyone, the true nature of those implied answers is more complex. Namely, the Speaker may, intentionally or due to a wrong assumption or difference of opinion, pose RQs implying answers which are not (or may not be) a part of the Addressee's Beliefs, and thereby of the Common Ground. Instead of treating implicit answers to RQs as obvious to everyone (and labeling RQs whose implied answers are not shared by the Addressee as failed ones), the approach presented in this paper redefines the nature of such implied answers, treating them as imposed rather than shared.

Based on the Speaker's communication style and his/her attitude towards the Addressee or a third party, RQs can be classified into three groups: aggressive (characterized by the Speaker's dominant attitude and forceful approach, and, as such, a convenient tool for attacking opponents and/or their views), friendly (those in which the persuasive effect is achieved in a way that is not threatening nor upsetting to the Addressee or a third party, and, as such, convenient for any communication that requires respectful approach), and sarcastic/ironical RQs (those that incorporate irony or sarcasm, whether with aggressive or friendly implications).

The analysis of the corpus, which included RQs from ten American movie scripts, showed that friendly RQs (52.23\%) outnumber the other two types (aggressive 33.2\%, and sarcastic/ironical 14.55\%), indicating that the use of RQs is more often associated with respectful rather than with an aggressive attitude. With respect to interlocutors' relationship, peer-to-peer RQs appeared to be most common, which can be attributed to the fact that most conversations in the selected corpus occur between peers. As for those in- 
stances where one of the interlocutors is in a superior position, superior-toinferior RQs make up almost three quarters $(73.87 \%)$ of RQs that occur in such interactions. While such huge discrepancy is mainly due to the prevalent use of aggressive and sarcastic/ironical RQs by superiors, even when it comes to friendly RQs it is more likely that RQs are posed by superiors rather than inferiors $(59.18 \%$ of friendly RQs that occur between people of different social status are asked by superiors). This finding is in line with the view of RQs as questions with imposed answers, as imposing one's view is less likely if the Speaker is in an inferior position.

Exploring the use of the above types of RQs in a specific context, such as online forums or political discourse, could be a topic of future research in this area.

\section{References}

Brown, Penelope, Stephen C. Levinson (1987). Politeness. Some Universals in Language Usage. Cambridge: Cambridge University Press.

Caponigro, Ivano, Jon Sprouse (2007). Rhetorical questions as questions. PuigWaldmüller, Estela, ed. Proceedings of Sinn und Bedeutung (11). Barcelona: Universitat Pompeu Fabra, 121-133. Retrieved from https://ojs.ub.unikonstanz.de/sub/index.php/sub/article/view/635/570

De Vries, Reinout E., Angelique Bakker-Pieper, Robert Alting Siberg, Kim van Gameren, Martijn Vlug (2009). The content and dimensionality of communication styles. Communication Research 36(2): 178-206. Retrieved from https:// www.researchgate.net/publication/249683210

Frank, Jane (1990). You call that a rhetorical question? Forms and functions of rhetorical questions in conversation. Journal of Pragmatics 14: 723-738.

Gibbs, Raymond W. (2000). Irony in talk among friends. Metaphor and Symbol 15(1): 5-27.

Han, Chung-hye (2002). Interpreting interrogatives as rhetorical questions. Lingua 112: 201--229.

Ilie, Cornelia (1994). What Else Can I Tell You? A Pragmatic Study of English Rhetorical Questions as Discursive and Argumentative Acts. Stockholm: Almqvist \& Wiksell International.

Ivanko, Stacey L., Penny Pexman, Kara M. Olineck (2004). How sarcastic are you? Individual differences and verbal irony. Journal of Language and Social Psychology 23: 244-271. Retrieved from https://www.researchgate.net/publication/ 247744086

Norton, Robert (1983). Communicator Style: Theory, Applications and Measures. Beverly Hills: Sage Publications.

Oraby, Shereen, Vrindavan Harrison, Lena Reed, Ernesto Hernandez, Ellen Riloff, Marilyn Walker (2016). Creating and characterizing a diverse corpus of sarcasm in dialogue. Fernandez, Raquel, Wolfgang Minker, Giuseppe Carenini, Ryuichiro Higashinaka, Ron Artstein, Alesia Gainer, eds. Proceedings of the 
17th Annual Meeting of the Special Interest Group on Discourse and Dialogue. Los Angeles: Association for Computational Linguistics, 31-41.

Roberts, Richard M., Roger J. Kreuz (1994). Why do people use figurative language? Psychological Science 5: 159-163.

Rohde, Hannah (2006). Rhetorical questions as redundant interrogatives. San Diego Linguistics Papers 2: 134-168.

Sadock, Jerrold M. (1974). Toward a Linguistic Theory of Speech Acts. New York: Academic Press.

Schaffer, Deborah (2005). Can rhetorical questions function as retorts? Is the Pope Catholic? Journal of Pragmatics 37: 433-460.

Stalnaker, Robert C. (2002). Common ground. Linguistics and Philosophy 25: 701-721.

Špago, Džemal (2017). Rhetorical questions or rhetorical uses of questions? Explorations in English Language and Linguistics 4.2: 102-115. https://doi.org/10.1515/ exell-2017-0009

Van Roy, Robert (2003). Negative polarity items in questions: Strength as relevance. Journal of Semantics 20: 239-273.

Yuan, Shupei, John C. Besley, Wenjuan Ma (2018). Be mean or be nice? Understanding the effects of aggressive and polite communication styles in child vaccination debate. Health Communication 34: 1-10. Retrieved from https://www. researchgate.net/publication/325027290_

Zwarts, Frans (1996). A hierarchy of negative expressions. Wansing, Heinrich, ed. Negation: A notion in focus. Berlin: Walter de Gruyter , 169-194.

\section{Corpus}

(Movie scripts, retrieved December 19, 2019):

Absolute Power (https://www.dailyscript.com/scripts/Absolute_Power.PDF)

Independence Day (https:/ / www.imsdb.com/scripts/Independence-Day.html)

JFK (https:// sfy.ru/?script=jfk)

Nixon (https://sfy.ru/?script=nixon1995)

No Country for Old Men (https://www.scripts.com/script-pdf/175)

The American President (http://www.dailyscript.com/scripts/american_president. html)

The Butler (https://www.scripts.com/script-pdf/24131)

The Program (https://www.imsdb.com/scripts/Program,-The.html)

The Shawshank Redemption (http://www.dailyscript.com/scripts/shawshank.html)

13 Days (https://www.dailyscript.com/scripts/13_days.html)

\section{Author's address:}

Džemal Špago

Vrapčići 76, 88000 Mostar

Bosnia and Herzegovina

E-mail: dzemal.spago@unmo.ba 
Džemal Špago: Rhetorical questions as aggressive, friendly or sarcastic/ironical questions with imposed answers

Received: April 13, 2020

Accepted for publication: July 21, 2020 